\title{
Alterações hematológicas e hemostasia na COVID-19: uma revisão de literatura
}

\author{
Hematological alterations and hemostasis in COVID-19: a literature review \\ Alteraciones hematológicas y hemostasia en COVID-19: revisión de la literatura
}

Recebido: 13/08/2021 | Revisado: 22/08/2021 | Aceito: 25/08/2021 | Publicado: 27/08/2021

\author{
Ana Flávia Pereira \\ ORCID: https://orcid.org/0000-0003-2453-9572 \\ Universidade José do Rosário Vellano, Brasil \\ E-mail: anafpereira16@outlook.com \\ Ana Karolina Aparecida Terra \\ ORCID: https://orcid.org/0000-0002-0035-1295 \\ Universidade José do Rosário Vellano, Brasil \\ E-mail: karol_apterra@outlook.com \\ Carlos Henrique Santos Oliveira \\ ORCID: https://orcid.org/0000-0003-4959-8149 \\ Universidade José do Rosário Vellano, Brasil \\ E-mail: carlos.unifenas@gmail.com \\ Michele Caroline Terra \\ ORCID: https://orcid.org/0000-0003-4139-4256 \\ Universidade José do Rosário Vellano, Brasil \\ E-mail: michelecaroline_2012@hotmail.com \\ Carla Miguel de Oliveira \\ ORCID: https://orcid.org/0000-0003-2812-7647 \\ Universidade Federal de Alfenas, Brasil \\ E-mail: carla_oliveira03@hotmail.com \\ Layla Pereira de Carvalho \\ ORCID: https://orcid.org/0000-0003-4447-2221 \\ Universidade José do Rosário Vellano, Brasil \\ E-mail: layla.carvalho09@gmail.com \\ Sofia de Castro Oliveira \\ ORCID: https://orcid.org/0000-0002-1863-2079 \\ Universidade José do Rosário Vellano, Brasil \\ E-mail: sofiadecastrooliveira@ hotmail.com \\ Kamila Oliveira de Luca Rotondo \\ ORCID: https://orcid.org/0000-0002-7808-0755 \\ Universidade José do Rosário Vellano, Brasil \\ E-mail: Kamilaoliveira959@gmail.com \\ Letícia Mendonça Botelho \\ ORCID: https://orcid.org/0000-0002-3854-7410 \\ Universidade José do Rosário Vellano, Brasil \\ E-mail: lbot.botelho@gmail.com \\ Camila dos Santos Oliveira \\ ORCID: https://orcid.org/0000-0002-0262-885X \\ Universidade José do Rosário Vellano, Brasil \\ E-mail: camila-de-oliveira@ outlook.com \\ Felipe Fidelis Camilo \\ ORCID: https://orcid.org/0000-0002-3812-4012 \\ Universidade José do Rosário Vellano, Brasil \\ E-mail: felipe.camilo@aluno.unifenas.br \\ Ana Carolina Lima Delmoro \\ ORCID: https://orcid.org/0000-0002-5827-080X \\ Universidade José do Rosário Vellano, Brasil \\ E-mail: ana.delmoro@aluno.unifenas.br \\ Bruno Cesar Correa Salles \\ ORCID: https://orcid.org/0000-0002-4444-9673 \\ Universidade José do Rosário Vellano, Brasil \\ E-mail: bruno.alfenas@hotmail.com
}

\section{Resumo}

A COVID-19 é uma doença infecciosa causada pelo vírus SARS-CoV-2, o qual pertence à nova cepa do coronavírus, identificado na China no início de dezembro de 2019. Essa infecção apresenta sintomas leves e graves, podendo levar à Síndrome Respiratória Aguda Grave. Dessa forma, a necessidade de um perfil hematológico laboratorial da infecção 
pelo SARS-CoV-2 e seu monitoramento, torna-se de grande valia para auxiliar no prognóstico e tratamento da doença. Esta revisão sistemática tem como objetivo traçar o perfil hematológico decorrente da infecção pelo vírus SARS-CoV2, identificando as principais alterações encontradas no leucograma, eritrograma e plaquetograma. Para a elaboração deste estudo foi realizada uma busca eletrônica em diversos bancos de dados. As alterações hematológicas mais frequentemente encontradas foram linfopenia, leucopenia, neutrofilia associada à leucocitose, eosinopenia, redução de hemoglobina, trombocitopenia e agregação plaquetária, além das alterações morfológicas. A anemia não foi observada de forma notável, mas a redução da hemoglobina foi evidente em relação a pacientes saudáveis. Os fatores de coagulação associados à redução de plaquetas assim como a sua hiper ativação foram alterados em pacientes graves. Essas alterações demonstram o estado de hipercoagulabilidade presente em pacientes graves com COVID-19, resultando em quadros de microtrombos em vários órgãos, sendo está uma das complicações mais graves da COVID-19. Sendo assim, a contagem de plaquetas e as alterações dos parâmetros associados às plaquetas são atualmente uma preocupação. Contudo, com o levantamento realizado, fica evidente que a inflamação associada a um dano oxidativo elevado irá comprometer a hemostasia e fisiologia leucocitária de pacientes com COVID-19.

Palavras-chave: COVID-19; Vírus da SARS; Hemograma; Plaquetas; Linfócitos; Índices de Eritrócitos.

\begin{abstract}
The COVID-19 is an infectious disease caused by the SARS-CoV-2 virus, which belongs to the new strain of the coronavirus, identified in China in early December 2019. This one presents symptoms and serious conditions, which can lead to Severe Acute Respiratory Syndrome. Thus, the need for a laboratory hematological profile of SARS-CoV2 infection and its monitoring, becomes of great value to assist in the prognosis and treatment of the disease. This systematic review aims to trace the hematological profile resulting from infection by the SARS-CoV-2 virus, identifying the main changes found in the leukogram, erythrogram and platelet chart. For the elaboration of this study, an electronic search was carried out in several databases. The most frequently found hematological changes were lymphopenia, leukopenia, neutrophilia associated with leukocytosis, eosinopenia, reduced hemoglobin, thrombocytopenia and platelet aggregation, in addition to morphological changes. Anemia was not noticeably observed, but the reduction in hemoglobin was evident in healthy patients. The coagulation factors associated with platelet reduction as well as its hyper activation were altered in critically ill patients. These changes demonstrate the state of hypercoagulability present in critically ill patients with COVID-19, present in microthrombus pictures in various organs, being one of the most serious complications of COVID-19. Therefore, platelet count and changes in parameters associated with platelets are currently a concern. However, with the survey carried out, it is evident that an inflammation associated with high oxidative damage will compromise the hemostasis and leukocyte physiology of patients with COVID-19.
\end{abstract}

Keywords: COVID-19; SARS virus; Blood count; Platelets; Lymphocites; Erythrocyte Indices.

\title{
Resumen
}

COVID-19 es una enfermedad infecciosa causada por el virus SARS-CoV-2, que pertenece a la nueva cepa de coronavirus, identificada en China a principios de diciembre de 2019. Esta infección presenta síntomas leves y severos, que pueden derivar en Síndrome Respiratorio Agudo Grave. Por lo tanto, la necesidad de un perfil hematológico de laboratorio de la infección por SARS-CoV-2 y su seguimiento, se vuelve de gran valor para ayudar en el pronóstico y tratamiento de la enfermedad. Esta revisión sistemática tiene como objetivo rastrear el perfil hematológico resultante de la infección por el virus SARS-CoV-2, identificando los principales cambios encontrados en el leucograma, eritrograma y tabla de plaquetas. Para la elaboración de este estudio se realizó una búsqueda electrónica en varias bases de datos. Los cambios hematológicos más frecuentemente encontrados fueron linfopenia, leucopenia, neutrofilia asociada a leucocitosis, eosinopenia, hemoglobina reducida, trombocitopenia y agregación plaquetaria, además de cambios morfológicos. La anemia no se observó de forma notable, pero la reducción de la hemoglobina fue evidente en los pacientes sanos. Los factores de coagulación asociados con la reducción de plaquetas así como su hiperactivación se alteraron en pacientes críticamente enfermos. Estos cambios demuestran el estado de hipercoagulabilidad presente en pacientes críticamente enfermos con COVID-19, resultando en imágenes de microtrombos en varios órganos, que es una de las complicaciones más graves del COVID-19. Por lo tanto, el recuento de plaquetas y los cambios en los parámetros asociados con las plaquetas son actualmente una preocupación. Sin embargo, con la encuesta realizada, es evidente que la inflamación asociada a un alto daño oxidativo comprometerá la hemostasia y la fisiología leucocitaria de los pacientes con COVID-19.

Palabras clave: COVID-19; Virus del SARS; Conteo de glóbulos; Plaquetas; Linfocitos; Índices de eritrocitos.

\section{Introdução}

A COVID-19 é uma doença infecciosa causada pelo vírus SARS-CoV-2, o qual pertence à nova cepa do coronavírus, identificado na cidade de Wuhan no início de dezembro de 2019 (Guan et al., 2020). No entanto, antes do surto epidêmico do SARS-CoV-2, os surtos mais recentes foram os causados pelos vírus SARS-CoV e MERS-CoV que ocorreram na China em 
2003 e no Oriente Médio em 2012, respectivamente. Por pertencerem à mesma família, eles compartilham inúmeras semelhanças (Fehr; Perlman, 2015).

Essa infecção pode apresentar desde sintomas mais leves, como febre, tosse seca, coriza e fadiga até sintomas mais graves, como pneumonia viral, podendo levar à Síndrome Respiratória Aguda Grave (SARS) e até ao óbito. Dependendo da anamnese do paciente, ou seja, idosos e pacientes que apresentem alguma comorbidade tendem a desenvolver sintomas mais graves (Zhang et al., 2020).

Independente dos sintomas, a infecção pelo SARS-CoV-2 acontece pelas vias aéreas dependente da expressão de uma enzima que tem sido relatada como ponto chave da alta disseminação da doença na população. A enzima ECA2 (enzima conversora de angiotensina 2) é encontrada em muitos tipos de células e tecidos, principalmente nos pulmões. Além disso, é encontrado nos pneumócitos tipo 2, que são células localizadas nos alvéolos, onde o oxigênio é trocado pelo dióxido de carbono (Hamming; Times; Bulthuis Lely; Navis; Goor, 2004).

O SARS-CoV-2 infecta as células através dessas enzimas, ou seja, a ECA2 é a porta de entrada para o vírus infectar uma série de células humanas. Isso faz com que as células liberam fatores de processos inflamatórios e ativam macrófagos presentes nos alvéolos, os quais são importantes na indução de citocinas inflamatórias que recrutam muitas células do sistema imune para infiltrar nos pulmões. Essa ativação imunológica adicional causa inflamação e danos teciduais, podendo contribuir na evolução da doença (Hamming; Timens; Bulthuis Lely; Navis; Goor, 2004) (Sun et. al., 2020).

Desta forma, a necessidade de um perfil hematológico laboratorial da infecção pelo SARS-CoV-2 e seu monitoramento, torna-se de grande valia para o prognóstico e tratamento da doença. O hemograma completo avalia quantitativamente e qualitativamente toda a linhagem hematopoiética e é utilizado para diagnosticar infecções que são frequentes no Brasil (Failace; Fernandes, 2015). Logo, pode ser utilizado com a finalidade de auxiliar no diagnóstico de pacientes com COVID-19, e otimizar o acompanhamento clínico.

Para avaliar esses aspectos em pacientes com COVID-19 é necessário avaliar os parâmetros hematológicos relacionados aos leucócitos, hemácias e plaquetas. Sendo assim, esta revisão de literatura tem como objetivo geral, traçar o perfil hematológico na infecção pelo vírus SARS-CoV-2, e como objetivo específico, identificar as alterações encontradas no leucograma, eritrograma e plaquetograma de pacientes com COVID-19, e suas correlações.

\section{Metodologia}

O trabalho realizado não envolveu o uso de dados de seres humanos nem qualquer tipo de avaliação clínico-laboratorial e, assim, não necessitou de aprovação pelo Comitê de Ética. O estudo trata-se de uma revisão de literatura sobre o tema utilizando de revistas acadêmicas científicas, artigos científicos e livros (Pereira et. al., 2018). Os artigos foram obtidos de bancos de dados, tais como Scielo, Pubmed, Elsevier, Science Direct e Google Scholar, de modo que comparasse diferentes informações encontradas nestas plataformas, listando as principais condições que abordam os marcadores hematológicos na COVID-19. Foram pesquisados artigos utilizando os seguintes descritores: COVID-19, vírus da SARS, hemograma, leucócitos, eritrócitos, plaquetas, índices de eritrócitos e ciclooxigenase. Os critérios de inclusão foram artigos publicados entre 2000 e 2020, originais, em língua portuguesa e inglesa, que obedeçam às palavras chaves descritas. Foram excluídos editoriais, artigos de revisão, opiniões e revistas com Qualis Capes inferior a B2 ou Fator de Impacto abaixo de 1,0.

\section{Resultados e Discussão}

Durante a elaboração desta revisão sistemática, com o resultado do processo de busca e seleção nos bancos de dados e revistas científicas eletrônicas foram encontrados 137 artigos sobre o tema abordado, porém apenas 2 livros didáticos e 51 artigos 
científicos relacionados ao presente estudo foram catalogados. Os demais trabalhos foram excluídos por não atenderem aos objetivos do presente estudo, e por se adequarem aos critérios de exclusão. Os artigos incluídos neste estudo que abordaram as alterações hematológicas foram listados abaixo (Tabela 1).

Tabela 1 - Resumo dos artigos que abordaram alterações hematológicas.

\begin{tabular}{|c|c|c|}
\hline Hemograma & $\begin{array}{l}\text { Alteração } \\
\text { característica } \\
\text { encontrada }\end{array}$ & Autores \\
\hline \multirow{7}{*}{ Leucograma } & Leucopenia & Qin et al., (2020); Huang, C. et al., (2020); Guan et al., (2020); Ye et al., (2020) \\
\hline & Linfopenia & $\begin{array}{l}\text { Zhang, J. et al., (2020); Fan et al., (2020); Qin et al., (2020); Huang, C. et al., (2020); } \\
\text { Wang, F. et al., (2020); Diao et al., (2020); Guan et al., (2020); Sun et al., (2020); } \\
\text { Wang, D. et al., (2020); Zheng et al., (2020); Chen, R. et al., (2020); Ye et al., (2020); } \\
\text { Ding et al., (2020); Chen, N. et al., (2020); Yuan et al., (2020); Huang, Y. et } \\
\text { al., (2020); Wang, Lizhen et al., (2020); Blomme et al., (2020); Guclu et al., (2020); } \\
\text { Bao et al., (2020) }\end{array}$ \\
\hline & Leucocitose & $\begin{array}{c}\text { Sun et al., (2020); Wang, D. et al., (2020); Ye et al., (2020); Blomme et al., (2020); } \\
\text { Guclu et al., (2020) }\end{array}$ \\
\hline & Neutrofilia & $\begin{array}{c}\text { Fan et al., (2020); Sun et al., (2020); Wang, D. et al., (2020); Zheng et al., (2020); Ye } \\
\text { et al., (2020); Blomme et al., (2020); Chen, R. et al., (2020); Guclu et al., (2020); Bao } \\
\text { et al., (2020) }\end{array}$ \\
\hline & Aumento de NLR & $\begin{array}{c}\text { Qin } \text { et al., (2020); Ye et al., (2020); Ding et al., (2020); Zheng et al., (2020); Chen, R. } \\
\text { et al., (2020) }\end{array}$ \\
\hline & Eosinopenia & $\begin{array}{c}\text { Zhang, J. et al., (2020); Qin et al., (2020); Chen, R. et al., (2020); Xie et al., (2020); } \\
\text { Tan et al., (2020) }\end{array}$ \\
\hline & $\begin{array}{c}\text { Alterações } \\
\text { Morfológicas }\end{array}$ & Fan et al., (2020); Zini et al., (2020); Nazarullah et al., (2020); Jones e Ireland (2020) \\
\hline \multirow[t]{3}{*}{ Eritrograma } & $\begin{array}{l}\text { Redução de } \\
\text { Hemoglobina }\end{array}$ & $\begin{array}{l}\text { Fan } \text { et al., (2020); Huang, C. et al., (2020); Sun et al., (2020); Guan et al., (2020); } \\
\text { Chen, N. et al., (2020); Yuan et al., (2020); Huang, Y. et al., (2020); Wang, Lizhen et } \\
\text { al., (2020); Blomme et al., (2020); Lazarian et al., (2020); Djakpo et al., (2020); } \\
\text { Wang, C. et al., (2020); Algassim et al., (2020); Torti et al., (2020); Bellmann-Weiler } \\
\text { et al., (2020); Lansiaux et al., (2020); Mironova et al., (2020) }\end{array}$ \\
\hline & RDW aumentado & Foy et al., (2020); Wang, C. et al., (2020) \\
\hline & $\begin{array}{l}\text { Alterações } \\
\text { Morfológicas }\end{array}$ & Jones e Ireland (2020) \\
\hline \multirow{6}{*}{$\begin{array}{l}\text { Plaquetogra } \\
\text { ma }\end{array}$} & Trombocitopenia & $\begin{array}{l}\text { Chen, R. et al. (2020); Wang, X. et al., (2020); Wang, Lang et al. (2020); Manne et al., } \\
\text { (2020); Bao et al., (2020); Tang et al., (2020); Guclu et al., (2020); Zhang, S. et al., } \\
\text { (2020); Huang, C. et al., (2020); Guan et al., (2020) }\end{array}$ \\
\hline & Trombocitose & Wang, Lang et al., (2020); Taha et al., (2020) \\
\hline & $\begin{array}{c}\text { Alterações } \\
\text { Morfológicas }\end{array}$ & Zini et al., (2020); Jones e Ireland (2020); Taha et al., (2020) \\
\hline & $\begin{array}{l}\text { Agregação } \\
\text { Plaquetária }\end{array}$ & Guclu et al., (2020); Hottz et al., (2020); Manne et al., (2020); Taha et al., (2020) \\
\hline & PDW aumentado & Guclu et al., (2020); Zhang, S. et al., (2020) \\
\hline & VPM aumentado & Guclu et al., (2020); Taha et al., (2020); Zhang, S. et al., (2020) \\
\hline
\end{tabular}


Entre os 51 artigos utilizados nesta produção científica, 25 (49,01\%) artigos abordaram alterações leucocitárias em geral, porém 20 artigos demonstraram que pacientes infectados com o vírus SARS-CoV-2 apresentaram um quadro evidente de linfopenia, sendo a alteração hematológica mais frequente e mais acentuada em quadros graves da doença. Em 3 dos 20 artigos, os linfócitos T CD4, T CD8 e NK estavam abaixo dos níveis normais, mas a diminuição do linfócito T CD4 foi mais evidente em casos graves. As células B também encontraram-se reduzidas, porém dentro do nível inferior da faixa. Destes 25 artigos, 4 apresentaram quadros de leucopenia, os quais são provenientes da redução de linfócitos.

Quadros de neutrofilia foram demonstrados em 9 do total de artigos utilizados, mas somente em 5 artigos relatou-se o aumento de leucócitos totais (leucocitose) possivelmente associado ao aumento de neutrófilos. O aumento de neutrófilos em razão dos linfócitos (NLR) também foi encontrado aumentado em 5 artigos, o qual indica um fator de risco para o agravamento da doença e mortalidade de pacientes com COVID-19. Além dessas alterações encontradas no leucograma, os eosinófilos foram encontrados reduzidos em 5 dos 51 artigos utilizados.

Por outro lado, 19 (37,25\%) artigos relataram alterações eritrocitárias no geral, sendo que 17 artigos abordaram uma redução de hemoglobina bem evidente no eritrograma, explicando o quadro de hipóxia que ocorre na COVID-19. A anemia não foi notada em todos os casos, mas a redução de hemoglobina é bem evidente quando comparada a pacientes saudáveis. Essa redução de hemoglobina foi relacionada ao aparecimento de quadros anêmicos durante a internação em 4 artigos, sendo que em 1 deles torna evidente o desenvolvimento de um primeiro caso de anemia hemolítica.

Alterações plaquetárias em geral foram demonstradas em 14 (27,45\%) artigos dos 51 artigos revisados, sendo que 10 artigos relataram quadros de trombocitopenia (redução da contagem de plaquetas) e 2 artigos retratam quadros de trombocitose (aumento da contagem de plaquetas). A agregação plaquetária foi encontrada em 4 artigos. Além dessas alterações, o VPM e o PDW foram encontrados aumentados em 3 e 2 artigos, respectivamente. Alterações na morfologia plaquetária observadas no esfregaço sanguíneo também foram relatadas em 3 artigos, onde foram encontradas a presença de plaquetas gigantes, geralmente hipercromáticas e vacuolizadas, megacariócitos, e também grandes aglomerados de plaquetas.

Na população chinesa com COVID-19, estudos têm demonstrado a presença de leucopenia, ou seja, baixo nível de glóbulos brancos no sangue durante a internação, basicamente às custas de linfopenia moderada, podendo evoluir para grave (Fan et al., 2020. Quin et al., 2020) (Huang et al., 2020). A linfopenia (baixo nível de linfócitos) na COVID-19 parece ser a alteração hematológica mais frequente, pois ela funciona como biomarcador de gravidade da infecção, logo, os linfócitos podem ser utilizados como triagem para diagnóstico de exames e para monitoramento da evolução de casos graves (Blomme; Smets; Ranst; Boeckx; Laer, 2020).

Estudos feitos com pacientes da cidade de Wuhan, na China, demonstraram que os linfócitos T e NK estavam abaixo dos níveis normais, e as células B se encontram reduzidas, mas dentro do nível inferior da faixa. Porém, as células T (T CD4 e T CD8) foram as mais afetadas e que sofreram uma redução mais relativa, onde a diminuição do linfócito T CD4 foi mais evidente em casos graves e as células T CD8 não apresentaram diferenças estatísticas entre casos graves e casos leves (Quin et al., 2020) (Wang et al., 2020). De acordo com Diao et al. (2020), de 499 pacientes em estado grave, 75,95\% e 71,54\% dos pacientes apresentaram contagens notavelmente baixas de células T CD4 e TCD8, respectivamente.

Em uma pesquisa realizada com pacientes da China, 83,2\% dos pacientes apresentaram linfopenia e 33,7\% apresentaram leucopenia. Este mesmo autor relata que a leucopenia e linfopenia estão diretamente associadas à gravidade da COVID-19 (Guan et al., 2020). Dados similares haviam sido publicados recentemente demonstrando que na admissão hospitalar os pacientes apresentaram quadros de leucopenia e linfopenia (Huang et al., 2020). Isto pode aumentar de forma significativa a susceptibilidade a infecções bacterianas secundárias em COVID-19 grave. 
O autor Sun et al. (2020) demonstrou que a linfopenia está presente em pacientes em estado grave, entretanto, o autor não observou uma redução de leucócitos, e sim um aumento de neutrófilos, o que poderia justificar a normalidade ou aumento dos leucócitos totais (leucocitose). A justificativa segundo o autor para a linfopenia estaria na redistribuição dos linfócitos para os sítios de infecção com um aumento no consumo e associados a uma hematopoiese ineficaz.

Contudo, Wang et al. (2020), relata em seu estudo que 41 casos graves de COVID-19 apresentaram níveis crescentes de leucócitos e neutrófilos, resultando em leucocitose e neutrofilia. A neutrofilia pode estar associada à tempestade de citocinas induzida pela invasão do vírus em resposta aos linfócitos, e proveniente de infecções bacterianas secundárias (Wang et al., 2020) (Zheng et al., 2020). Níveis elevados dessas citocinas são responsáveis por causar danos aos tecidos pelo fato de gerar uma série de respostas imunes, desencadeando insuficiência respiratória ou insuficiência de múltiplos órgãos. A interleucina 6 é uma das principais citocinas aumentadas no sangue em pacientes não sobreviventes, indicando que níveis elevados desta interleucina condiz com quadros fatais de infecção pelo SARS-CoV-2 (Qin et al., 2020; Chen et al., 2020).

A NLR (razão de neutrófilos para linfócitos) é outro marcador importante na avaliação da progressão e prognóstico de pacientes infectados pelo SARS-CoV-2, devido às grandes alterações na contagem de linfócitos. O aumento de NLR representa um aumento significativo de neutrófilos com redução de linfócitos. Segundo Ye et al. (2020) em uma análise de 72 pacientes com COVID-19, linfopenia e leucopenia ocorreram em 54,2\% e 27,8\% dos pacientes, respectivamente. Nesse mesmo estudo, a contagem de leucócitos e neutrófilos, e a proporção de neutrófilos para linfócitos (NLR) foram relativamente maiores, visto que, o NLR elevado indica um fator de risco para o agravamento da doença e mortalidade de pacientes com COVID-19.

O mesmo foi relatado pelos autores Qin et al (2020) Zheng et al (2020) Ding et al (2020), os quais dizem que a maioria dos pacientes além de apresentarem linfopenia, também apresentaram um aumento de neutrófilos em razão dos linfócitos (NLR) em pacientes em estado grave. Juntamente com o aumento de neutrófilos e de NLR, há um aumento de procalcitonina (marcador útil de infecção bacteriana sistêmica) indicando possíveis quadros de infecções bacterianas secundárias, devido ao sistema imunológico desregulado (Qin et al., 2020).

Um perfil parecido foi observado no estudo realizado por Sun et al (2020), no qual a redução de linfócitos em pacientes com quadros graves levam ao mau funcionamento do sistema imune, e os predispõe a uma possível infecção bacteriana, o que justificaria o aumento da contagem de neutrófilos (neutrofilia), associado ao aumento do número de leucócitos (leucocitose). Estes resultados são extremamente importantes, pois poderão estar associados a uma maior taxa de mortalidade em pacientes com COVID-19 grave, contribuindo assim na condução do curso clínico em uma progressão desfavorável.

Além dos linfócitos se apresentarem reduzidos na maioria dos pacientes graves e fatais, encontrou-se níveis baixos de eosinófilos, associando-se à gravidade da doença e ao resultado clínico (Chen et al., 2020). Os eosinófilos são as principais células brancas encontradas em infecções parasitárias e reações alérgicas, mas também desempenham funções vitais em nosso organismo na defesa contra vírus e bactérias, pelo fato de sintetizar, armazenar e liberar uma gama de citocinas.

Segundo Tan; Zhou; Zhou; Hu; Long (2020), 82,5\% dos pacientes com quadros graves de COVID-19 apresentaram uma redução na contagem de eosinófilos. E acredita-se que a eosinopenia pode ser causada pelo aumento do recrutamento de células nas vias aéreas e tecidos infectados pelo vírus SARS-CoV-2, e/ou pela diminuição na liberação da medula óssea, devido a supressão da medula óssea causada pelo vírus, resultando em danos no microambiente medular perfeito (Xie; Ding; Han; Yin; Lu; Zhang, 2020).

Pacientes com baixa contagem de eosinófilos estavam mais propensos aos sinais clínicos da COVID-19, como febre, falta de ar e fadiga, em relação a aqueles com eosinófilos normais (Xie; Ding; Han; Yin; Lu; Zhang, 2020). Isso significa que a atenção deve ser redobrada no monitoramento de eosinófilos circulantes no sangue periférico, pois contagens baixas podem estar relacionadas a estágios graves, e ao mesmo tempo, o aumento de eosinófilos no sangue pode indicar um bom prognóstico. 
Portanto, de acordo com Zhang et al. (2020), a contagem de eosinófilos juntamente com linfócitos pode ser muito útil no auxílio do diagnóstico de infecção pelo vírus SARS-CoV-2 em pacientes suspeitos com sintomas típicos.

As alterações morfológicas encontradas nas células sanguíneas induzidas pela COVID-19 podem retratar danos sugestivos desencadeados pelo SARS-CoV-2 na hematopoiese. Os autores Fan et al. (2020) e Jones (2020) após analisar microscópicamente o esfregaço do sangue periférico de pacientes infectados com linfopenia, relatou que a maioria das amostras continham a presença de linfócitos reativos, dos quais pareciam ser do tipo plasmocitóide. De acordo com os estudos de Zini; Bellesi; Ramundo; d'Onofrio (2020), após a observação de esfregaços sanguíneos de 40 casos de pacientes diagnosticados com COVID-19, as anormalidades morfológicas mais encontradas incluem a presença de granulações escuras no citoplasma (semelhantes à granulações tóxicas), neutrófilos Pseudo Pelger-Huet (hiposegmentados), células apoptóticas e poucos linfócitos reativos (Quadro 1).

Por outro lado, estavam presentes no estágio inicial da doença, granulócitos imaturos como mielócitos e metamielócitos. As células apoptóticas apareceram com cromatina nuclear liquefeita e com citoplasma granulado e/ou azul, apontando assim as possíveis origens dessas células, isto é, proveniente de neutrófilos e linfócitos Zini; Bellesi; Ramundo; d'Onofrio (2020). Este estudo está em concordância com o de Nazarullah; Liang; Villarreal; Higgins; Mais (2020), o qual analisou o esfregaço sanguíneo de 12 pacientes infectados pelo SARS-CoV-2, e em todos houve a presença de neutrófilos Pseudo Pelger-Huet, e linfócitos plasmocitóides. Em 50\% dos casos, foram observados neutrófilos monoblastos (Quadro 1). 
Quadro 1 - Anomalias Morfológicas encontradas em esfregaços sanguíneos de pacientes infectados pelo SARS-CoV-2.

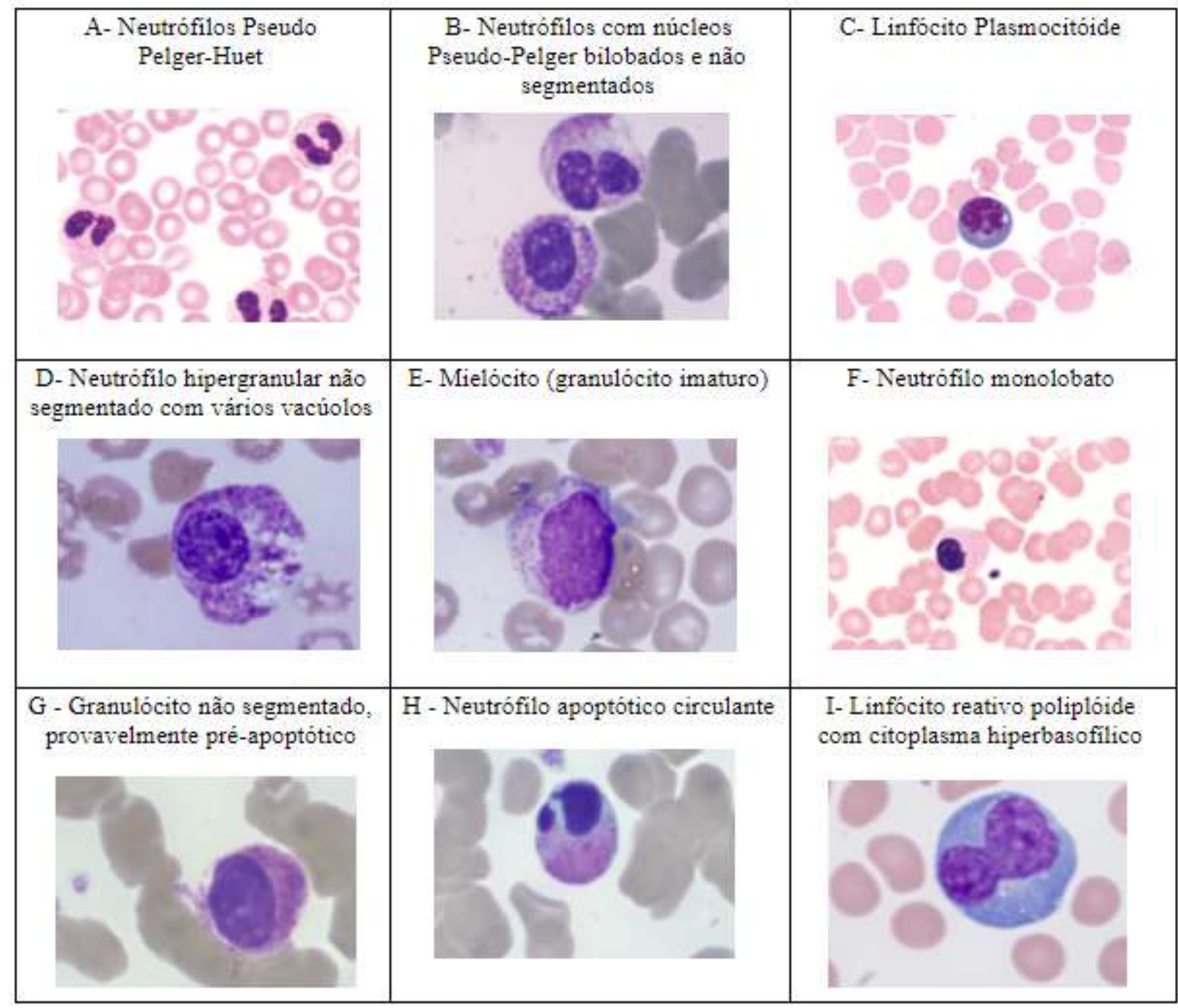

Fonte: Adaptado de Zini et al. (2020), Nazarullah et al. (2020).

No entanto, apesar de poucos estudos e publicações que avaliam a morfologia dos leucócitos, Zini; Bellesi; Ramundo; d'Onofrio (2020) Nazarullah; Liang; Villarreal; Higgins; Mais (2020) relatam que as alterações morfológicas encontradas em quadros de COVID-19 como a hipergranulação e a presença de neutrófilos Pseudo Pelger-Huet reduziram drasticamente após a eliminação do vírus. Após o tratamento, houve uma significativa mudança no quadro hematológico, onde se encontrou um frequente aumento de linfócitos.

Em relação ao eritrograma, estudos demonstraram que pacientes em estágio grave da doença e criticamente enfermos apresentaram uma redução dos níveis de hemoglobina e podem apresentar valores diminuídos de eritrócitos no sangue periférico, por outro lado, pacientes em estágio mais leve, apresentaram valores maiores de hemoglobina (Huang et al., 2020; Chen et al., 2020; Yuan et al., 2020). Em 2010 Reade; Weissfeld; Angus; Kellum; Milbrandt já havia demonstrado que é comum quadros de anemia em pacientes com pneumonia adquirida e que está relacionada a uma alta taxa de mortalidade quando níveis de hemoglobina estão abaixo de $10 \mathrm{~g} / \mathrm{dL}$.

Os autores Guan et al (2020) Huang et al (2020) demonstraram que a diminuição da concentração da hemoglobina em pacientes com a COVID-19 é mais evidente em quadros graves, compreendendo admissão à UTI, necessidade de ventilação mecânica e/ou óbito, em relação aos quadros não graves. Esta diferença foi observada quando foram comparados os valores de 
hemoglobina dos pacientes graves com os pacientes não graves. Os pacientes não graves apresentaram taxas de hemoglobina que se assemelham com as taxas de hemoglobina de pacientes saudáveis.

A anemia não foi comumente encontrada em pacientes com COVID-19, mas a redução de hemoglobina em relação aos valores normais foi bem evidente (Sun et al., 2020) (Huang et al., 2020). E a média dos valores dos índices eritrocitários (VCM, HCM, CHCM) encontrados no hemograma de diversos estudos em pacientes infectados pelo vírus SARS-CoV-2 estavam dentro da normalidade (Foy et al., 2020) (Wang et al., 2020) (Djakpo; Wang; Zhang; Chen; Chen; Antoine, 2020). Este relato pode ser explicado pelo fato de que mesmo os níveis de hemoglobina serem encontrados reduzidos, encontram-se dentro dos valores de normalidade. Dessa forma, essa redução não caracteriza um quadro de anemia, e se torna significativa quando comparada com pacientes sem a COVID-19 ou sem estar em estado grave. Talvez por isso não estejam sendo observadas alterações nos índices eritrocitários.

O mesmo foi relatado por Chen et al. (2020), o qual menciona que a anemia não é um achado laboratorial muito comum em pacientes infectados pelo vírus SARS-CoV-2, porém a hemoglobina apresentava-se reduzida em $51 \%$ de 99 pacientes infectados relatados pelo Hospital Jin Yin-tan. Por outro lado, segundo Huang et al (2020) em 41 pacientes com COVID-19, a concentração de hemoglobina dos pacientes graves foi menor $(12,2 \mathrm{~g} / \mathrm{dL})$ em relação aos pacientes sem cuidados na UTI $(13,0$ g/dL). Outros estudos também relataram redução nos níveis de hemoglobina em 38,2 \% (Huang et al., 2020) e 19,23\% (Wang et al., 2020) dos pacientes hospitalizados devido à infecção pelo SARS-CoV-2. Em um paciente idoso diagnosticado com COVID-19, além de níveis reduzidos de hemoglobina, foram encontrados glóbulos vermelhos nucleados com pontilhados basofílicos associados à diseritropoiese (Jones, 2020).

Segundo Sun et al. (2020), 116 pacientes infectados pelo SARS-CoV-2 foram avaliados e divididos em três grupos: comum na admissão, UTI grave (admitidos em unidade de terapia intensiva) e não UTI grave (não admitidos em UTI), onde se encontrou uma redução da concentração de hemoglobina nos três grupos, sendo mais notável no grupo de UTI grave. Sob outra perspectiva, de 259 pacientes hospitalizados por conta da COVID-19, 24,7\% apresentavam anemia na admissão, sendo quadros de anemia leve em 14,7\%, de moderada em $8,1 \%$, e de grave em 1,9\%. Porém, a porcentagem de pacientes anêmicos aumentou para $68,8 \%$ durante a internação. Os indivíduos já admitidos com quadro anêmico apresentaram permanência mais longa no hospital e uma taxa de mortalidade mais alta (Bellmann-Weiler et al., 2020).

Os autores Blomme; Smets; Ranst; Boeckx; Laer (2020) em seu estudo, também dividiu os pacientes infectados pelo SARS-CoV-2 em três grupos (UTI - recuperado, UTI - não recuperado e falecidos), notando uma redução de hemoglobina em todos os três grupos, mas sem diferenças significativas entre eles. Este fato pode desencadear quadros de anemia, os quais podem ser explicados pela diminuição da eritropoiese e aumento dos danos aos glóbulos vermelhos, devido ao aumento de fatores inflamatórios desencadeados pela COVID-19. Ainda segundo este autor, os pacientes apresentaram anemia leve, e a concentração de hemoglobina em pacientes com COVID-19 relacionados à pacientes com Influenza A, mostrou-se ser significativamente mais baixa, sugerindo uma maior influência do vírus SARS-CoV-2 nos glóbulos vermelhos (Blomme; Smets; Ranst; Boeckx; Laer, 2020).

Entretanto o autor Lazarian et al. (2020) em publicação recente abordou em seu estudo realizado em seis hospitais franceses e belgas que sete pacientes desenvolveram um primeiro caso de anemia hemolítica autoimune (AHAI) durante a infecção pelo vírus SARS-CoV-2. Os níveis de hemoglobina reduziram em mais de $3 \mathrm{~g} / \mathrm{dL}$ em todos os casos, e o tempo médio entre os primeiros sinais clínicos da COVID-19 e o início do aparecimento da anemia hemolítica foi de nove dias. A concentração média da hemoglobina no instante do diagnóstico da anemia hemolítica era de $7 \mathrm{~g} / \mathrm{dL}$, juntamente com sinais de hemólise aparentes.

No início da AHAI, todos os pacientes apresentaram marcadores de inflamação elevados (proteína $\mathrm{C}$ reativa, fibrinogênio e dímeros D). Em todos os setes pacientes com COVID-19 que desenvolveram AHAI, o teste direto de antiglobulina 
(TAD) apresentou resultado positivo, seja para IgG, para C3d ou para IgG e C3d. Os anticorpos anti-eritrócitos foram anticorpos quentes em quatro casos, sendo dois de especificidade $\operatorname{IgG}$ e dois $\operatorname{IgG}+\mathrm{C} 3 \mathrm{~d}$, e aglutininas frias em três casos, sendo dois de especificidade C3d e um IgG + C3d (Lazarian et al., 2020). O TAD (ou Coombs direto) verifica se o eritrócito está sensibilizado por algum anticorpo produzido pelos linfócitos $\mathrm{B}$, pois ao ser sensibilizado, ficará marcado e ao passar pelo processo de hemocaterese no baço, os eritrócitos são reconhecidos pelos macrófagos esplênicos, sendo destruídos (Failace; Fernandes, 2015). Em um estudo publicado recentemente, o autor analisou dados do hemograma de 208 pacientes com COVID-19 leve e comum internados em um hospital na China. Desses pacientes, 53 possuíam comorbidades como hipertensão, doença cardíaca coronária, diabetes mellitus e doenças respiratórias, os quais apresentaram hemoglobina inferior $(12,48 \mathrm{~g} / \mathrm{dL})$, hematócrito reduzido (37,45\%) e níveis de hemácias ligeiramente mais baixos (3,19 milhões/ $\mu \mathrm{L}$ ) (Djakpo, D. K. et al, 2020). Segundo este mesmo autor, essas alterações podem ser explicadas devido a danos pulmonares induzidos pela COVID-19 e pela impossibilidade da medula óssea de produzir hemácias suficientes, pois a COVID-19 associada à presença de comorbidades pode afetar a produção de hemácias devido à inflamação existente (Djackpo, D. K. et al.,2020).

Fica evidente que a redução de hemoglobina está diretamente relacionada com o agravamento da COVID-19 e com a redução da saturação de oxigênio, pelo fato que a saturação de oxigênio é função da concentração de hemoglobina. Uma redução na concentração de hemoglobina resulta na redução da capacidade do transporte do oxigênio, e sucessivamente no conteúdo arterial de oxigênio $\left(\mathrm{CaO}^{2}\right)$ (Algassim, A. A. et al, 2020). A baixa saturação de oxigênio $(<90 \%)$ é comumente encontrada em pacientes sintomáticos indicando quadros graves, enquanto que a saturação de oxigênio $>90 \%$ indicam quadros moderados (Guclu, E. et al, 2020). Portanto, medir a saturação de oxigênio pode auxiliar os médicos a identificar os pacientes que podem precisar de ventilação mecânica ou de altos níveis de oxigênio durante a internação (Akhavan, A. R. et al, 2020).

Os índices eritrocitários (glóbulos vermelhos, hemoglobina e hematócrito) foram relativamente diminuídos em pacientes do grupo grave no estudo publicado por (Wang, C. et al, 2020), ao mesmo tempo que o RDW (parâmetro morfológico) se encontrou significativamente maior no grupo grave. Essas alterações podem resultar em quadros de anemia, e aparecer em decorrência dos danos imunológicos que suprimem a medula óssea, envolvendo um grande número de glóbulos vermelhos imaturos no sangue periférico, hiperplasia da linhagem eritróide, e apoptose dos glóbulos vermelhos, o que acabaria prejudicando o tamanho e a morfologia dos mesmos.

Esses fatores citados acima acabam por desencadear um aumento na largura de distribuição dos glóbulos vermelhos (Wang C. et al, 2020). Um RDW aumentado representa um resultado negativo no diagnóstico de diversos distúrbios pelo fato de estar associado a um risco elevado de morbidade e mortalidade, por outro lado, fornece importantes informações no prognóstico de curto e longo prazo, pelo fato de apontar uma intensa desregulação da eritropoiese (Foy, B. H. et al, 2020). De acordo com Foy, B. H. et al (2020), 1641 pacientes diagnosticados com COVID-19 apresentaram RDW maior que 14,5\% na admissão com um risco maior de mortalidade de $31 \%$, ao mesmo tempo que, pacientes com RDW menor ou igual a $14,5 \%$ tinham um risco menor (11\%). Pacientes em que o RDW aumentou durante a admissão, também apresentaram risco aumentado de mortalidade.

Em uma publicação recente, Algassim, A. A. et al (2020) menciona que após a admissão de pacientes com COVID-19, encontrou-se uma diminuição progressiva nos níveis de hemoglobina dos pacientes internados, ou seja, 93 (37,6\%) dos pacientes de UTI e 43 (16,8\%) pacientes da enfermaria geral desenvolveram quadros anêmicos durante a internação. Essa redução de hemoglobina pode estar associada à inflamação desencadeada na COVID-19, devido a inúmeros mecanismos complicados, entre eles, a desregulação do metabolismo do ferro induzida por citocinas (Algassim, A. A. et al., 2020).

Sob outro aspecto, Bellmann-Weiler, R. et al. (2020) relatou em sua publicação que os biomarcadores do metabolismo do ferro estavam disponíveis em 222 pacientes diagnosticados com COVID-19. No momento da admissão, 194 pacientes possuíam uma anormalidade na homeostasia do ferro, e grande parte deles tinham deficiência funcional de ferro, induzidos pela 
inflamação. Os achados mais evidentes envolveram redução na concentração de ferro sérico, níveis elevados de ferritina, níveis reduzidos de transferrina e saturação da transferrina reduzida. Esses achados clínicos, associado à redução nos níveis de hemoglobina, representam o perfil laboratorial semelhante ao encontrado em pacientes com quadros de anemia de doença crônica. Entretanto, este mesmo autor relata que níveis elevados de ferritina e níveis baixos de transferrina foram associados a uma permanência mais longa no hospital, risco aumentado de admissão na UTI e a necessidade de ventilação mecânica (Bellmann-Weiler, R. et al., 2020).

Alguns estudos recentes demonstraram que o vírus SARS-CoV-2 interage com a cadeia $\beta$ do grupo heme da hemoglobina, dissociando o ferro e formando um complexo com a porfirina (Figura 1). Isso pode desencadear na disfunção e/ou na falta de hemoglobina transportadora de oxigênio e dióxido de carbono, possibilitando o desconforto e falência respiratória (Lansiaux, E. et al, 2020; Torti, L. et al, 2020) . Dessa forma, os íons de ferro dissociados do grupo heme podem se espalhar na corrente sanguínea e se distribuir para os tecidos, causando danos oxidativos e inflamação. Portanto, para tentar contornar essa situação, altas quantidades de ferritina são produzidas na tentativa de reduzir a oxidação e os danos teciduais, visto que, são proteínas de armazenamento do ferro (Mironova, G. D. et al., 2020) (Figura 2).

Figura 1 - Interação do vírus SARS-CoV-2 com a cadeia $\beta$ do grupo heme da hemoglobina.

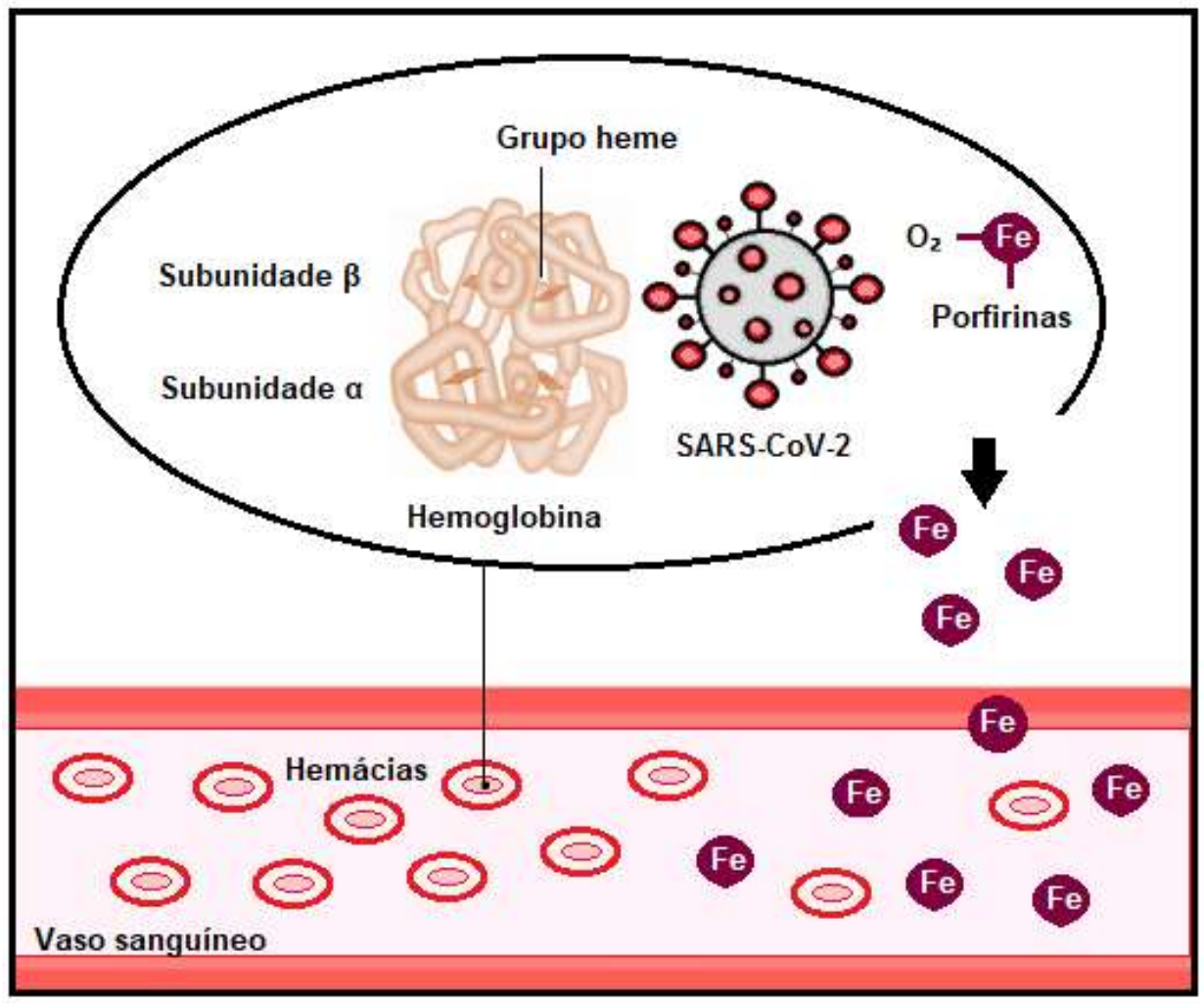

Fonte: Autores. 
Figura 2 - Proteína ferritina englobando o ferro, para a redução da oxidação e danos teciduais.

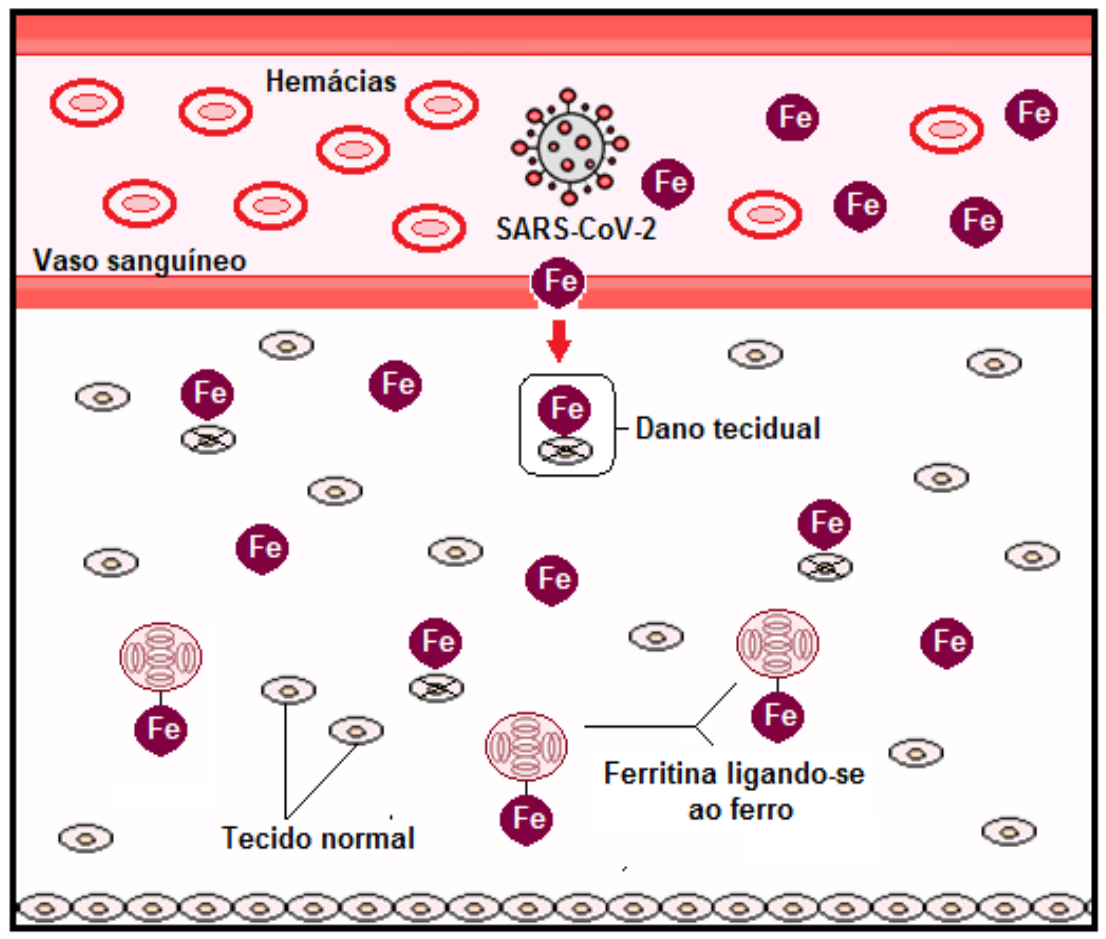

Fonte: Autores.

Além disso, as alterações encontradas nos índices plaquetários tem sido de grande valia no auxílio do prognóstico na COVID-19. Diversos estudos têm relatado uma relação entre os pacientes graves infectados pelo SARS-CoV-2 e os parâmetros de coagulação, entre eles redução na contagem de plaquetas, altos níveis de dímero D (produto de degradação específico produzido na hidrólise da fibrina), e tempo prolongado de protrombina (TP) e tromboplastina parcial ativada (TTPa). Essas alterações podem desencadear microtrombos em diversos órgãos, principalmente nos pulmões, pelo fato dos pacientes apresentarem hipercoagulabilidade, característica importante da inflamação (Huang, C. et al, 2020; Tang, N. et al, 2020; Wang, L. et al, 2020). Por isso, é importante monitorar as alterações hemostáticas durante o curso da doença.

Segundo (Tang, N. et al, 2020), a COVID-19 está ligada a uma coagulopatia proveniente do aumento de fatores coagulantes, tais como produtos de degradação da fibrina/fibrinogênio culminando no aumento dos níveis de dímero D, os quais estão associados com uma taxa maior de mortalidade. O tempo de protrombina (TP) e o tempo parcial de tromboplastina (TTPa) prolongados, e níveis de dímero D acima de $500 \mathrm{ng} / \mathrm{mL}$, foram encontrados em não sobreviventes. Este mesmo autor relata que de 21 pacientes não sobreviventes com COVID-19, 3 pacientes apresentaram níveis de dímero-D entre 1000 e 3000 ng/mL, enquanto que 18 pacientes apresentaram níveis acima de $3000 \mathrm{ng} / \mathrm{mL}$. As plaquetas também foram encontradas reduzidas em 7 pacientes com níveis entre 50 - $100 \times 10^{9} / \mathrm{L}$, e em 5 pacientes com níveis menores que 50 × 10/L.

A análise do tempo de protrombina em relação à gravidade da doença foi realizada em alguns estudos, nos quais o TP foi notado por maior tempo em pacientes com quadros graves de COVID-19. O prolongamento do TP foi mais visível em pacientes que vieram a óbito com valores superiores a 15 a 16 segundos (Tang, N. et al, 2020; Zhou, F. et al, 2020). Ao realizar uma análise em 191 pacientes com COVID-19 em Wuhan, Zhou, F. et al (2020) relatou a morte de 54 pacientes, e os fatores associados à mortalidade incluíram elevação de dímero D (> $1000 \mathrm{ng} / \mathrm{mL}$ ) na admissão, aumento do TP, elevações na interleucina 6 e de ferritina sérica, e outros biomarcadores de inflamação. Todos os 54 não sobreviventes apresentaram septicemia, e $50 \%$ apresentaram indícios de coagulopatia devido a um aumento de TP de 3 segundos ou um aumento de 5 segundos no TTPa. 
Em um estudo com 213 pacientes, 26 apresentaram trombocitopenia, enquanto que a trombocitose foi encontrada em 10 pacientes. O TP foi prolongado em 39 pacientes, e TTPa encontrou-se encurtado em 27 pacientes e prolongado em 56 pacientes. As concentrações de dímero D aumentaram em 123 pacientes. Entretanto, a contagem de plaquetas foi significativamente menor nos não sobreviventes em relação aos sobreviventes, ao mesmo tempo que o TP, TTPa e as concentrações de dímero D foram maiores naqueles que morreram. O TP prolongado na admissão foi considerado um forte indicador de pior resultado em pacientes infectados pelo SARS-CoV-2. Além disso, o TP e o TTPa prolongados nos não sobreviventes indicam a ativação da coagulação juntamente com o consumo dos fatores de coagulação, ao mesmo tempo que seu aumento está ligado ao risco de sangramento e associado à trombose (Wang, L. et al., 2020).

Ao analisar os dados de 5 pacientes durante a internação com COVID-19, (Wang, X. et al., 2020) encontrou picos de dímero D juntamente com TP prolongado e contagem de plaquetas reduzida. Entretanto, 4 desses pacientes já sofriam com comorbidades cardiovasculares e/ou cerebrovasculares. Segundo este mesmo autor, o aumento do dímero D durante a internação é um marcador de mau prognóstico em pacientes com COVID-19 que apresentem lesão cardíaca. Outro estudo semelhante estudou 99 pacientes e relatou que as plaquetas estavam abaixo da normalidade em 12 pacientes e acima da normalidade em quatro, enquanto que o dímero D estava aumentado em 36 pacientes (Chen, N. et al, 2020). O nível de dímero D também foi encontrado maior em não sobreviventes do que em sobreviventes, porém dentro da normalidade, e o TP prolongado (Wang, D. et al., 2020).

Em 2003 com a Síndrome Respiratória Aguda Grave (SARS) (Wong, R. S. et al., 2003) já havia relatado quadros semelhantes. De 157 pacientes, 87 apresentaram trombocitopenia durante a progressão da doença, sendo que a maioria deles desenvolveram trombocitopenia leve (plaquetas $\leq 140 \times 10^{9} / \mathrm{L}$ ), e somente 3 pacientes tinha uma contagem de plaquetas abaixo de $50 \times 10^{9} / \mathrm{L}$. No início da doença, a contagem de plaquetas era normal, ou seja, a trombocitopenia progrediu com o fim da primeira semana. Não houve indícios de sangramento entre os pacientes. Porém, a trombocitose (plaquetas $\geq 400 \times 10^{9} / \mathrm{L}$ ) também foi observada em 77 dos pacientes, onde as plaquetas atingiram o pico por volta do dia 17 da doença. Dentre esses, somente uma paciente apresentava plaquetas acima de $1000 \times 10^{9} / \mathrm{L}$. O TTPa foi encontrado prolongado em 96 pacientes.

De acordo com Bao, C. et al (2020), 49 de 178 pacientes foram diagnosticados com doença grave, e 129 pacientes com doença não grave, onde o grupo de doença grave apresentaram menor contagem de plaquetas e também parâmetros de coagulação anormal em relação ao grupo não grave: TP prolongado e aumento de dímero D. Dentre os casos graves que foram a óbito, 6 de 7 casos apresentaram trombocitopenia durante a internação, e a contagem de plaquetas reduziu posteriormente até a morte, enquanto que a trombocitopenia surgiu dentro de 1 semana após a admissão em 6 pacientes recuperados.

Outro estudo realizado por Guan, W. J. et al (2020) forneceu dados sobre as características clínicas de 1.099 casos de COVID - 19. Na admissão, 36,2\% apresentavam trombocitopenia $\left(<150 \times 10^{9} / \mathrm{L}\right)$, aumentando para $57,7 \%$ em pacientes internados na UTI. Entretanto, essa anormalidade hematológica foi mais evidente entre os casos graves. $\mathrm{O}$ achado mais comum nos pacientes com COVID-19 que apresentaram coagulopatia foi um aumento da concentração de dímero $\mathrm{D}$, uma diminuição na contagem de plaquetas e um prolongamento do TP. Esses encontrados explicam a trombocitopenia, a qual é agravada pelo consumo de plaquetas, podendo desencadear danos imunológicos às células sanguíneas, levando à produção de auto-anticorpos e imunocomplexos.

Em um artigo publicado recentemente, foram incluídos 215 pacientes com COVID-19, os quais foram divididos em dois grupos: grave (134 pacientes com saturação de oxigênio do ar ambiente <90\%) e moderado (81 pacientes com saturação de oxigênio $\geq 90 \%$ ). A trombocitopenia foi observada em 54 pacientes no dia da admissão à internação, e em 52 no terceiro dia de seguimento. Os achados encontrados mostraram que a saturação de oxigênio na admissão e a diferença do volume plaquetário médio (VPM) entre o primeiro e o terceiro dia de internação foram parâmetros relevantes em pacientes com COVID-19, visto 
que a mortalidade foi 8,4 vezes maior nos pacientes com saturação menor que $90 \%$ na admissão hospitalar, e o aumento de 1 unidade no VPM aumentou a mortalidade em 1,76 vezes entre o primeiro e o terceiro (Guclu, E. et al, 2020).

Ainda segundo Guclu, E. et al. (2020), os índices plaquetários como o VPM e a largura de distribuição plaquetária (PDW) foram encontrados mais elevados em não sobreviventes no dia de admissão e terceiro dia de acompanhamento, porém os valores plaquetários foram considerados normais em muitos pacientes na admissão. O aumento na produção de plaquetas ocorre à medida que a contagem de plaquetas reduz, havendo um número alto de plaquetas jovens, as quais são mais ativas do que as plaquetas mais velhas. Essas alterações podem esclarecer o aumento dos índices plaquetários.

No estudo de Zhang, S. et al . (2020), os pacientes com COVID-19 em quadros grave e criticamente grave em relação aos pacientes com COVID-19 leve e moderado, apresentaram parâmetros plaquetários anormais, envolvendo redução na contagem de plaquetas e micrócitos plaquetários (PCT), volume plaquetário médio (VPM) e largura de distribuição plaquetária (PDW) aumentados, bem como alterações nos parâmetros de coagulação. Por outro lado, pacientes com COVID-19 leve e moderado também manifestaram redução na contagem de plaquetas e VPM aumentado. O VPM aumentado em COVID-19 propõe que as plaquetas estejam hiperreativas, pelo fato do VPM se relacionar com a atividade plaquetária.

Juntamente com essas anormalidades laboratoriais, os pacientes apresentam taxas aumentadas de trombose pulmonar. Nesse contexto, o dano causado às células endoteliais ocasiona à ativação plaquetária, agregação e retenção das plaquetas e à formação de trombos no local lesionado, podendo desencadear na redução da trombopoiese (produção de plaquetas) e aumento no consumo, causando trombocitopenia, e contribuindo para a coagulopatia observada na COVID-19 (Guclu, E. et al, 2020; Hottz, E. D. et al, 2020; Huang, C. et al, 2020; Manne, B. K. et al, 2020). Este fato pode ser explicado por conta que a formação das plaquetas pode ocorrer nos pulmões, onde as plaquetas são liberadas dos megacariócitos maduros, e com a danificação dos pulmões, os megacariócitos são aprisionados, impedindo a liberação das plaquetas (Mandal, R. V. et al, 2007).

De acordo com Taha, M. et al (2020) em seu estudo, os pacientes com COVID-19 apresentaram plaquetas maiores e mais granulares juntamente com um volume plaquetário médio aumentado. Grandes aglomerados de plaquetas também foram observados, demonstrando um indício de ativação plaquetária e aumento da trombopoiese. Além disso, encontrou-se um aumento da fração de plaquetas imaturas, que geralmente são maiores e mais reativas. Plaquetas maiores apresentam grânulos mais densos, os quais armazenam uma ampla gama de moléculas biologicamente ativas, como glicoproteínas IIb/IIIa, fibrinogênio e fator de von Willebrand, os quais podem iniciar a cascata de coagulação durante a inflamação e determinar a agregação plaquetária (Santos, Paulo Caleb Júnior de Lima, 2012).

O autor Hottz, E. D. et al (2020) demonstrou que as plaquetas de pacientes com COVID-19 da UTI apresentaram agregação em relação com pacientes com infecção moderada por COVID-19. Por serem conhecidas por serem hiperreativas na inflamação, as plaquetas estão associadas diretamente ao risco trombótico. Isso também está de acordo com vários indícios que associam as plaquetas como células que atuam na inflamação e em respostas pró-trombóticas em muitas outras infecções virais (Hottz, E. D. et al, 2020; Mandal, R. V. et al, 2007; Manne, B. K. et al, 2020).

$\mathrm{O}$ aumento da ativação plaquetária associada a agregação pode estar relacionada com o aumento da geração e liberação de tromboxano A2, demonstrando que a infecção por SARS-CoV-2 está ligada à hiperreatividade plaquetária, e que o vírus pode alterar a expressão do gene plaquetário. Essas alterações podem desencadear quadros trombóticos em pacientes infectados pelo vírus SARS-CoV-2 (Manne, B. K. et al., 2020). Por outro lado, (Chen, J. S. et al., 2020) relatou que o vírus SARS-CoV-2 ao lesionar o endotélio pode estimular a enzima ciclooxigenase, gerando prostaglandina D 2 (PD2) e tromboxano A2. Isso faz com que ocorra hiper ativação plaquetária levando a estados pró-trombóticos, devido à degranulação das plaquetas e dos agonistas plaquetários, que é proveniente do estímulo dos receptores de tromboxano, os quais são ligados à proteína $\mathrm{G}$, ativando a fosfolipase C. 
No entanto, Violi, F. et al (2020) demonstrou que pacientes internados com COVID-19 apresentaram danos oxidativos proveniente da ativação do receptor de NOX-2 (NADPH oxidase-2), indicando um fator de agravamento da infecção com complicações trombóticas, pelo fato da NOX-2 provocar agregação plaquetária por meio da superprodução de peróxido de hidrogênio, isoprostano ou inativação de óxido nítrico. Estudos realizados demonstraram que o aumento de danos oxidativos associados ao aumento do colesterol LDL pode desencadear na hiper ativação plaquetária, e consequentemente na formação de trombos (Salles, B. C. C. et al., 2020). Portanto, se houver o agravamento da dislipidemia em quadros de COVID-19, o aumento da LDL oxidada irá ativar o receptor CD36 dentro das plaquetas e agravar ainda mais o quadro de ativação plaquetária, e a formação de trombos.

Anomalias na morfologia plaquetária também foi demonstrada no estudo de (Zini, G. et al., 2020), constatando principalmente a presença de plaquetas gigantes, geralmente hipercromáticas, vacuolizadas, sendo que algumas apresentavam pseudópodes, não apenas em pacientes com trombocitose, mas também naqueles com trombocitopenia. Por outro lado, Jones, J. R.; Ireland, R. (2020) também observaram no esfregaço sanguíneo a presença de trombocitopenia, plaquetas gigantes e, além disso, a presença de megacariócitos (células responsáveis pela produção de plaquetas na circulação). Os autores relataram que essas alterações podem ser provenientes de um distúrbio grave e reversível da mielopoiese em pacientes sintomáticos com COVID-19 (Zini, G. et al., 2020) .

\section{Conclusão}

De acordo com o levantamento realizado, fica evidente que a inflamação desencadeada associada a um dano oxidativo elevado que irá comprometer a hemostasia e fisiologia leucocitária de pacientes com COVID-19. Além disso, conclui-se que a enzima ciclooxigenase estimulada pelo vírus exerce um papel crucial nos eventos tromboembólicos, pelo fato de gerar marcadores inflamatórios como prostaglandinas e tromboxano A2, os quais são responsáveis por hiper ativar as plaquetas, causando agregação plaquetária. Por outro lado, observou-se que a leucopenia predispõe o paciente a uma imunodeficiência o que acarretará a uma neutrofilia, isso pode estar relacionado com um quadro de infecção secundária, anemia característica de doença crônica, apesar de não comum não se descarta a possibilidade de anemia do tipo hemolítica.

Sendo assim, medicamentos inibidores da enzima ciclooxigenase ou até mesmo antagonistas de tromboxano A2, podem ser usados de maneira a reduzir a evolução da coagulopatia na COVID-19. Contudo, o monitoramento dos índices hematológicos, principalmente dos índices plaquetários, se torna necessário na investigação da evolução da doença, sendo uma ferramenta útil na análise de pacientes com COVID-19.

Porém, relatos detalhados desses índices ainda são escassos na literatura, sendo preciso de mais estudos clínicos que possam corroborar nossos achados.

Com isso, diante dos achados apresentados neste trabalho, é de suma importância que o presente estudo tenha continuidade, com o intuito de identificar outras maneiras de danos causados pelo vírus, com isso fazer associações com os sinais e sintomas dos pacientes, a fim de melhorar a clínica do mesmo e, por fim, enriquecer a literatura para com a COVID-19.

\section{Referências}

Adapa, S., Aeddula, N. R., Konala, V. M., Chenna, A., Naramala, S., Madhira, B. R., Gayam, V., Balla, M., Muppidi, V., \& Bose, S. (2020). COVID-19 and Renal Failure: Challenges in the Delivery of Renal Replacement Therapy. Journal of Clinical Medicine Research, 12(5), 276-285.

Akhavan, A. R., Habboushe, J. P., Gulati, R., Iheagwara, O., Watterson, J., Thomas, S. et al. (2020). Risk Stratification of COVID-19 Patients Using Ambulatory Oxygen Saturation in the Emergency Department. Western Journal of Emergency Medicine, 21(6), 5-14.

Algassim, A. A., Elghazaly, A. A., Alnahdi, A.S., Mohammed-Rahim, O. M., Alanazi, A. G., Aldhuwayhi, N. A. et al. (2020). Prognostic significance of hemoglobin level and autoimmune hemolytic anemia in SARS-CoV-2 infection. Annals of Hematology, 100, 37-43. 
Bao, C., Tao, X., Cui, W., Yi, B., Pan, T., Young, K. H. et al. (2020). SARS-CoV-2 induced thrombocytopenia as an important biomarker significantly correlated with abnormal coagulation function, increased intravascular blood clot risk and mortality in COVID-19 patients. Experimental Hematology and Oncology, 9(16), $1-8$

Bellmann-Weiler, R., Lanser, L., Barket, R., Rangger, L., Schapfl, A., Schaber, M. et al. (2020). Prevalence and Predictive Value of Anemia and Dysregulated Iron Homeostasis in Patients with COVID-19 Infection. Journal of Clinical Medicine, 9(8), 2429.

Blomme, S., Smets, L., Ranst, M., V., Boeckx, N., Laer, C.V. (2020). The influence of COVID-19 on routine hematological parameters of hospitalized patients. Acta Clinica Belgica.

Chen, J. S., Alfajaro, M. M., Wei, J., Chow, R. D., Filler, R. B., Eisenbarth, S. C. et al.(2020). Cyclooxgenase-2 is induced by SARS-CoV-2 infection but does not affect viral entry or replication. BioRxiv.

Chen, N., Zhou, M., Dong, X., Qu, J., Gong, F., Han, Y. et al. (2020). Epidemiological and clinical characteristics of 99 cases of 2019 novel coronavirus pneumonia in Wuhan, China: a descriptive study. The Lancet, 395(10223), 507-513.

Chen, R., Sang, L., Jiang, M., Yang, Z., Jia, N. et al. (2020). Longitudinal hematologic and immunologic variations associated with the progression of COVID19 patients in China. Journal of Allergy and Clinical Immunology, 146 (11).

Diao, B., Wang, C., Tan, Y., Chen, X., Liu, Y. et al. (2020). Reduction and Functional Exhaustion of T Cells in Patients With Coronavirus Disease 2019 (COVID19). Frontiers Immunology, 11 (827).

Ding, X., Yu, Y., Lu, B., Huo, J., Chen, M., Kang, Y. et al. (2020). Dynamic profile and clinical implications of hematological parameters in hospitalized patients with coronavirus disease 2019. Clinical Chemistry and Laboratory Medicine (CCLM), 58 (8), p. 1365-1371.

Djakpo, D. K., Wang, Z., Zhang, R., Chen, X., Chen, P., Antoine, M. M. L. K. (2020). Blood routine test in mild and common 2019 coronavirus (COVID-19) patients. Bioscience reports, $40(8)$.

Failace, Renato., Fernandes, Flavo. (2020). Hemograma: manual de interpretação. 6. ed. Porto Alegre: Artmed.

Fan, B. E., Chong, V. C. L., Chan, S. S. W., Lim, G. H., Lim, K. G. E. et al. (2020). Hematologic parameters in patients with COVID-19 infection. American Journal of Hematology, 95(6), 131-134.

Fehr, A. R., Perlman S. (2015). Coronaviruses: An Overview of Their Replication and Pathogenesis. Methods in molecular biology, 1282, 1-23.

Foy, B. H., Carlson, J. C. T., Reinertsen, E., Valls, R. P. I., Lopez, R. P., Palanques-Tost, E. et al. (2020). Association of Red Blood Cell Distribution Width With Mortality Risk in Hospitalized Adults With SARS-CoV-2 Infection. JAMA Network, 3(9), 1-13.

Guan, W. J., Ni, Z. Y., Hu, Y., Liang, W. H., Ou, C. Q., He, J. X., et al. (2020). Clinical Characteristics of Coronavirus Disease 2019 in China. The New England Journal of Medicine, 382, 1708-1720.

Guclu, E., Kocayigit, H., Okan, H. D., Erkorkmaz, U., Yurumez, Y., Yaylac1, S. et al. (2020). Effect of COVID-19 on platelet count and its indices. Revista da Associação Médica Brasileira, 66 (8), 1122-1127.

Hamming, I., Timens, W., Bulthuis, M. L., Lely, A. T., Navis, G., Goor, H. (2004). Tissue distribution of ACE2 protein, the functional receptor for SARS coronavirus. A first step in understanding SARS pathogenesis. The Journal of pathology, 203(2), 631-637.

Hottz, E. D., Azevedo-Quintanilha, I. G., Palhinha, L., Teixeira, L., Barreto, E. A., Pão, C. R. R. et al. (2020). Platelet activation and platelet-monocyte aggregate formation trigger tissue factor expression in patients with severe COVID-19. Blood, 136(11), 1330-1341.

Huang, C., Wang, Y., Li, X., Ren, L., Zhao, J., Hu, Y. et al. (2020). Clinical features of patients infected with 2019 novel coronavirus in Wuhan, China. The Lancet, 395 (10223), 497-506.

Huang, Y., Tu, M., Wang, S., Chen, S., Zhou, W., Chen, D. et al. (2020). Clinical characteristics of laboratory confirmed positive cases of SARS-CoV-2 infection in Wuhan, China: A retrospective single center analysis. Travel medicine and infectious disease, 36.

Jones, J. R., Ireland, R. (2020). Morphological changes in a case of SARS-CoV-2 infection. Blood, 135(25), 2324

Lansiaux, E., Pébaÿ, P. P., Picard, J. L., Son-Forget, J. (2020). COVID-19: beta-thalassemia subjects immunised? Medical Hypotheses, 142.

Lazarian, G., Quinquenel, A., Bellal, M., Siavellis, J., Jacquy, C., Re, D. et al. (2020) Autoimmune haemolytic anaemia associated with COVID-19 infection. British Journal of Haematology, 190, 29-31.

Mandal, R. V., Mark, E. J., Kradin, R. L. (2007). Megakaryocytes and platelet homeostasis in diffuse alveolar damage. Experimental and Molecular Pathology, 83(3), 327-331.

Manne, B. K., Denorme, F., Middleton, E. A., Portier, I., Rowley, J. W., Stubben, C. et al. (2020). Platelet gene expression and function in patients with COVID19. Blood, 136(11), 1317-1329.

Mironova G. D, Belosludtseva N. V, Ananyan M. A. (2020). Prospects for the use of regulators of oxidative stress in the comprehensive treatment of the novel Coronavirus Disease 2019 (COVID-19) and its complications. European Review Medical and Pharmacological sciences, 24, 8585-8591.

Nazarullah, A., Liang, C., Villarreal, A., Higgins, A. R., Mais, D. D. (2020). Peripheral Blood Examination Findings in SARS-CoV-2 Infection. American Journal of Clinical Pathology, 154, 319-329. 
Pereira A. S. et al. (2018). Metodologia da pesquisa científica. [Free e-book]. Santa Maria/ RS. Ed. UAB/NTE/ UFSM.

Qin, C., Zhou, L., Hu, Z., Zhang, S., Yang, S., Tao, Y. et al. (2020). Dysregulation of Immune Response in Patients With Coronavirus 2019 (COVID-19) in Wuhan, China. Clinical Infectious Diseases, 71, 762-768.

Reade, M. C., Weissfeld, L., Angus, D. C., Kellum, J. A., Milbrandt, E. B. (2010). The prevalence of anemia and its association with 90-day mortality in hospitalized community-acquired pneumonia. BMC pulmonary medicine, 10, 10-15.

Salles, B. C. C., Silva, A. M., Taniguthi, L., Ferreira, J. N., Rocha, C. Q., Vilegas, W. et al. (2020). Passiflora edulis Leaf Extract: Evidence of Antidiabetic and Antiplatelet Effects in Rats. Biological and Pharmaceutical Bulletin, 43(1), 169-174.

Santos, Paulo., Caleb, Júnior de Lima. (2012). Métodos e interpretação: hematologia clínica. Roca.

Sun, S., Cai, X., Wang, H., He, G., Lin, Y., Lu, B. et al. (2020). Abnormalities of peripheral blood system in patients with COVID-19 in Wenzhou, China. Clinica Chimica Acta, 507, 174-180.

Taha, M., Sano, D., Hanoudi, S., Esber, Z., Elahi, M., Gabali, A. et al. (2020). Platelets and renal failure in the SARS-CoV-2 syndrome. 32(1), $130-137$.

Tang, N., Li, D., Wang, X., Sun, Z. (2020). Abnormal coagulation parameters are associated with poor prognosis in patients with novel coronavirus pneumonia. Journal of Thrombosis and Haemostasis, 18, 844-847.

Tan, Y., Zhou, J., Zhou, Q., Hu, L., Long, Y. (2020). Role of eosinophils in the diagnosis and prognostic evaluation of COVID-19. Journal Medical Virology.

Torti, L., Maffei, L., Sorrentino, F., Fabritiis, P., Miceli, R., Abruzzese, E. (2020). Impact of SARS CoV-2 in Hemoglobinopathies with Immune Disfunction and Epidemiology. A Protective Mechanism from Beta Chain Hemoglobin Defects?. Mediterranean journal of hematology and infectious diseases, 12 (1), 1-3.

Violi, F., Oliva, A., Cangemi, R., Ceccarelli, G., Pignatelli, P., Carnevale, R. et al. (2020). Nox2 activation in Covid-19. Redox Biology, 36, 1-4.

Wang, C., Deng, R., Gou, L., Fu, Z., Zhang, X., Shao, F. et al. (2020). Preliminary study to identify severe from moderate cases of COVID-19 using combined hematology parameters. Annals of translational medicine, 8 (9), 593.

Wang, D., Hu, B., Hu, C., Zhu, F., Liu, X., Zhang, J. et al. (2020). Clinical Characteristics of 138 Hospitalized Patients With 2019 Novel Coronavirus-Infected Pneumonia in Wuhan, China. JAMA,. 323 (11), 1061-1069.

Wang, F., Nie, J., Wang, H., Zhao, Q., Xiong, Y., Deng, L. et al. (2020). Characteristics of Peripheral Lymphocyte Subset Alteration in COVID-19 Pneumonia. The Journal of infectious diseases, 221 (11), 1762-1769.

Wang, L., Duan, Y., Zhang, W., Liang, J., Xu, J., Zhang, Y. et al. (2020). Epidemiologic and Clinical Characteristics of 26 Cases of COVID-19 Arising from Patient-to-Patient Transmission in Liaocheng, China. Clinical epidemiology, 12, 387-391.

Wang, L., He, WB., Yu, XM., Hu, DL., Jiang, H. (2020). Prolonged prothrombin time at admission predicts poor clinical outcome in COVID-19 patients. World Journal of Clinical Cases, 8(19), 4370-4379.

Wang, X., Du, B., Li, J., Wang, S., Wang, X., Guo, M. et al. (2020). D-dimer surge and coagulation disorders in COVID-19 related pneumonia patients with cardiac injury: Clinical Case Report, 99(31), 1-6.

Wong, R. S., Wu, A., To, K. F., Lee, N., Lam, C. W., Wong, C. K. et al. (2003). Haematological manifestations in patients with severe acute respiratory syndrome: retrospective analysis. BMJ, 326 (7403), 1358-1362.

Xie, G., Ding, F., Han, L., Yin, D., Lu, H., Zhang, M. (2020). The role of peripheral blood eosinophil counts in COVID-19 patients. Allergy, 1-12.

Yuan, X., Huang, W., Ye, B., Chen, C., Huang, R., Wu, F. et al. (2020) Changes of hematological and immunological parameters in COVID-19 patients. International journal of hematology, 112(4), 553-559.

Ye, W., Chen, G., Li, X., Ji, C., Hou, M., Zhang, G. et al. (2020). Dynamic changes of D-dimer and neutrophil-lymphocyte count ratio as prognostic biomarkers in COVID-19. Respiratory Research, 21 (69).

Zhang, J. J., Dong, X., Cao, Y. Y., Yuan, Y. D., Yang, Y. B., Yan, Y. Q. et al. (2020) Clinical characteristics of 140 patients infected with SARS-CoV-2 in Wuhan, China. Allergy, 75(7), 1730-1741.

Zhang, S., Liu, Y., Whang, X., Yang, L., Li, H., Whang, Y. et al. (2020). SARS-CoV-2 binds platelet ACE2 to enhance thrombosis in COVID-19. Journal of Hematology and Oncology, 3(120), 1-22.

Zheng, Y., Zhang, Y., Chi, H., Chen, S., Peng, M., Luo, L. et al. (2020). The hemocyte counts as a potential biomarker for predicting disease progression in COVID-19: a retrospective study. Clinical Chemistry and Laboratory Medicine (CCLM), 58 (7), 1106-1115.

Zhou, F., Yu, T., Du, R., Fan, G., Liu, Y., Liu, Z. et al. (2020). Clinical course and risk factors for mortality of adult patients hospitalized with COVID-19 in Wuhan, China: a retrospective cohort study. The Lancet, 395, 1054-1062.

Zini, G., Bellesi, S., Ramundo, F., d'Onofrio, G. (2020). Morphological anomalies of circulating blood cells in COVID-19. American Journal of Hematology, $95,870-872$. 